\title{
Metacognitive and Self Regulated Learning Strategies Profiles: An Exploratory Survey of a Group of High School Students
}

\author{
De Stasio, Simona \\ Department of Human Studies, Lumsa University, Rome \\ Email: s.destasio@lumsa.it \\ Di Chiacchio, Carlo \\ Invalsi Rome \\ Email: carlo.dichiacchio@invalsi.it
}

Doi:10.5901/mjss.2015.v6n4s3p656

\begin{abstract}
In the present study the relation between metacognitive and self regulated learning strategies and academic performance was explored. Research objectives were: (a) to highlight the presence of homogeneous subgroups of students on metacognitive and self regulated learning strategies and (b) to test group differences on academic performance. Learning Strategies Questionnaire (QSA), (Pellerey,1996) was administered to 647 students with an average age of 18.6 years $(S D=1.04)$ attending their 4th or 5th year of high school. QSA measures 14 factors: 7 cognitive, 7 affective and motivational. Cluster analysis evidenced the presence of three types of students in using learning strategies. The results have highlighted the profile of student efficacy on the one hand, with a efficacious strategic and motivational aspects related to study. On the other hand, there are two profiles of weaker students: first type shows an insufficiency in both cognitive and affective-motivational aspects, the second one evidences an inadequacy of emotion regulation compensated for by sufficient cognitive strategies. The three groups showed, as expected, significant differences in their academic achievement. Findings are discussed in theoretical and applicative terms.
\end{abstract}

Keywords: metacognition, self regulated learning strategies, academic performance, high school students

\section{Introduction}

Over the past few decades, metacognition has emerged as a crucial topic of research interest in cognitive and educational psychology. Metacognition is a term that was coined by Flavell in 1970s. Metacognitive knowledge is used to monitor and regulate cognitive processes such as reasoning, comprehension, problem solving, learning and so on (Credé and Phillips, 2012; De Stasio and Di Chiacchio 2008;Pintrich 2000; Winne 1996). Because metacognition has a predictive role in successful learning, it is relevant to study metacognitive activity to determine how students can better apply their cognitive resources through metacognitive control. Metacognition includes many dimensions of student development, ranging from academic abilities to awareness of the self as learner. Students are said to be metacognitive to the degree to which they are engaged in thinking about themselves, the nature of learning tasks, and the social contexts (Artino 2009; Brown 1980; Cleary and Chen; 2009). The effective learners are those who are aware of their strengths and limitations and find ways to remedy the latter (Bransford et al., 1999).

Research on study processes outlined the basic role of school learning with regard to attention strategies and their elaboration and organisation, including the awareness of the student's own cognitive processes in carrying out appropriate monitoring (Zimmerman, 1999).

The ability to focus on a specific task for an adequate period of time and with a sufficient level of concentration represents an unavoidable component for studying with profit (Johnston and Dark, 1986; Anderson, 1982). The processing of knowledge, the ability, that is, to connect new knowledge to what has already been learnt, enables the student to consciously understand and remember new information (Anderson,1990).

Metacognitive and self-regulation models of learning (Zimmerman, 1999, Clear and Zimmerman, 2012) demonstrate how scholastic and academic performance is the function of sensitive cognitive processes involved in learning. Individuals through self-regulation are able to adapt to the environment, modifying their own knowledge and behaviour (Pintrich, Zunsho 2002; Winne, 1996). 
Metacognitive and self-regulated learning strategies are vital factors for learner successful (Bol and Garner, 2011). Self-regulated learning is referred to "an active, practical process in which learners determine goals for process of learning and to monitor, regulate their cognition, motivation, and behavior, guided by their goals and the contextual characteristics of the learning environment" (Pintrich, 2000). Students are encouraged to select and modify their learning strategies, and reflect on the effectiveness of their learning strategies in order to become active in their learning process (Clear and Zimmerman, 2012).

From the methodological point of view, most of the studies concerning the relationship between learning strategies and academic performance used linear analysis techniques such as multiple regression, factorial analysis, or more recently, profile analysis

Entwisle and Brennan (1971) had already pointed out that this type of approach is based on the hypothesis that there is only one equation that well describes the profiles of learning process skills. More recent studies have shown how important it is to carry out an in depth qualitative study of students and their metacognitive, and motivational dimensions regarding to study activity (De Beni and Pazzaglia,2003; Di Chiacchio and De Stasio 2011; Montalvo and Torres 2004; Moliterni et al.2011; Proctor et al.2006).

It was to be expected, therefore, that there was not a single equation of regression or a unique profile, but rather a series of profiles which although indistinguishable on the performance level in quantitative terms, they express different metacognitive and self-regulation patterns.

Given these research premises, the present study aims to highlight the presence of homogenous sub-groups of students on metacognitive, self regulatory and motivational functioning and to analyse the relationship between the use of study strategies and academic performance.

\section{Method}

\subsection{Participants}

The sample consisted of 647 Italian students with an average age of 18.6 years (SD=1.04) attending their 4th or 5th year of high school (humanistic, scientific, technical and psycho-pedagogical schools). With regard to gender, there were more females than males (51 \% females and $49 \%$ males) and medium socioeconomic status (6.2\% high and 93.8\% medium ) was predominant.

Subjects were recruited at six different schools in which the head of the school had authorized the researchers to collect data after the approval of students' parents. The research was conducted following APA's (2010) ethical guidelines and code of conduct.

\subsection{Instrument}

Learning Strategies Questionnaire (QSA), (Pellerey,1996) was administered to assess the cognitive, emotional and motivational components of learning. The QSA is a self-report instrument that evaluates 14 factors: 7 cognitive factors (elaboration strategies, self-regulation, disorientation, collaboration, use of a semantic graphic organiser, concentration difficulties, self-interrogation) and 7 emotional and motivational factors (anxiety, will, attribution to controllable causes, lack of perseverance, competence perception, emotional interference). Responses are given on a 4-point scale, with participants required to evaluate each item in terms of the frequency with which they experience the strategy described, ranging from 0 (never) to 4 (always).In the current study Cronbach's alpha of the scale-questionnaire is 0.80 .

\subsection{Procedure}

Participants were asked to fill in the questionnaire concerning study strategies. The average response time was about 15 minutes. At the end of the academic year their final result in mathematics and Italian were registered and were considered indices of their academic performance

\section{Data Analysis}

Cluster analysis was performed to analyse the student sub-groups; hierarchical technique was employed (Ward's method was used for the agglomeration of data, while Euclidian quadratic distance assessed the dissimilarity measurement). The dendrogram examination and fusion co-efficient revealed the presence of 2 or 3 or 4 clusters. These three solutions were 
tested by employing a new analysis that incorporated the k-means method and utilised the derivatives from the hierarchical solutions as initial centroids.

Subsequently, in order to examine the coherence of the classification obtained, the agreement between the hierarchical and the non-hierarchical solution was taken, using Cohen's Kappa coefficient (Barbaranelli, 2006). The results showed a coefficient higher than .60 , thus indicating a reliable consistency between the two classification techniques.

Given the exploratory nature of the cluster analysis and the fact that more than one plausible solution was present in the data, a double cross-classification was carried out in order to verify the stability of the solutions and choose the best option. The results of this procedure showed the 3 cluster solutions to be the most stable, and consequently it was decided to choose this solution. Furthermore, the analyses of the dendrogram appeared to be more efficient.

In order to better analyse the differences between the identified clusters, a Multivaried Variance Analysis (Manova) was carried out. The Manova had the twofold purpose: to verify the presence of a multivaried effect on the classification variables and to identify which of the measurements used distinguished the groups at a univaried level. Besides the variables that made up the clusters in the analyses, academic performance was added as an ulterior descriptive variable.

\section{Results}

The Manova results showed a statistically significant multivaried and univaried effect on all the dependent variables utilised. It is interesting to note that more than $50 \%$ of the difference between the clusters is explained by the multivaried component (Table 3 also shows the dimension of the effect at a univaried level).

Table 1. Degree of Concordance Between Hierarchical and K-mean Solution

\begin{tabular}{ccc}
\hline Solutions & Cohen's Kappa & $p$ \\
\hline 2 cluster & 0,73 & 0,000 \\
3 cluster & 0,57 & 0,000 \\
4 cluster & 0,62 & 0,000 \\
\hline
\end{tabular}

In order to better understand the direction of the differences between the clusters, multivaried and univaried post-hoc comparisons were made by pairing off the groups (Barbaranelli, 2006). The first comparison regarded clusters 1 and 2. The Manova revealed a statistically significant multivaried effect that explained more than $70 \%$ of variability. The univaried comparisons confirmed the difference between the two groups in all the dependent variables considered (see Table 4).

Table 2. Results of Double Cross Classification by Cluster Solution

\begin{tabular}{ccc}
\hline Solutions & Average Cohen's Kappa & $\mathrm{p}$ \\
\hline 2 cluster & 1,00 & 0,000 \\
3 cluster & 0,76 & 0,000 \\
4 cluster & 0,36 & 0,000 \\
\hline
\end{tabular}

The second comparison was between clusters 1 and 3. The multivaried test also resulted statistically significant, explaining more than $70 \%$ of the difference between these two groups. The univaried comparisons illustrated that the two groups did not show significant differences in the variables: collaboration; use of semantic organisers; self-questioning; attribution to controllable causes (see Table 5). Finally, the last comparison regarded clusters 2 and 3. The multivaried test resulted significant with an extensive effect (approximately $70 \%$ of the difference between the two clusters was explained by the linear combination of the variables). At a univaried level, the groups did not display any significant differences in the variables: disorientation; attribution to uncontrollable causes; lack of perseverance. Table 3 illustrates the results of the comparisons. 
Table 3. Results of MANOVA: Univariate effect

\begin{tabular}{lcccccc}
\hline Dependent Variable & Type III Sum of Squares & df & Mean Square & $\mathrm{F}$ & Sig. & Partial $\eta^{2}$ \\
\hline Average grades in Math and Italian & 49,294 & 2 & 24,647 & 29,071 &, 000 &, $087^{\mathrm{b}}$ \\
Elaboration strategies & 559,556 & 2 & 279,778 & 87,546 &, 000 &, $224^{\mathrm{a}}$ \\
Self-regulation & 982,800 & 2 & 491,400 & 222,818 &, 000 &, $423^{\mathrm{a}}$ \\
Disorientation & 769,344 & 2 & 384,672 & 161,179 &, 000 &, $347^{\mathrm{a}}$ \\
Collaboration & 38,956 & 2 & 19,478 & 5,109 &, 006 &, $017^{\mathrm{c}}$ \\
Use of semantic-graphic organisers & 206,769 & 2 & 103,385 & 27,964 &, 000 &, $084^{\mathrm{b}}$ \\
Concentration difficulties & 602,245 & 2 & 301,123 & 92,710 &, 000 &, $234^{\mathrm{a}}$ \\
Self-interrogation & 292,675 & 2 & 146,337 & 41,308 &, 000 &, $120^{\mathrm{b}}$ \\
Anxiety & 873,006 & 2 & 436,503 & 163,265 &, 000 &, $350^{\mathrm{a}}$ \\
Volition & 1123,548 & 2 & 561,774 & 239,057 &, 000 &, $441^{\mathrm{a}}$ \\
Attribution to controllable causes & 567,382 & 2 & 283,691 & 96,860 &, 000 &, $242^{\mathrm{a}}$ \\
Attribution to incontrollable causes & 458,002 & 2 & 229,001 & 74,538 &, 000 &, $197^{\mathrm{a}}$ \\
Lack of perseverance & 779,583 & 2 & 389,791 & 162,228 &, 000 &, $348^{\mathrm{a}}$ \\
Self-competence & 257,303 & 2 & 128,651 & 40,980 &, 000 &, $119^{\mathrm{b}}$ \\
Emotional interferences & 620,125 & 2 & 310,062 & 114,546 &, 000 &, $274^{\mathrm{a}}$ \\
a = large effect size. & & & & & & \\
b = medium effect size. & & & & & & \\
c low effect size. & & & & & &
\end{tabular}

Controllable Causes: Finally, the last comparison concerned cluster 2 and cluster 3. The multivaried test had a significant result with a very extensive effect (approximately $70 \%$ of the difference between the two clusters was explained by the linear combination of the variable. At a univaried level, the groups showed no significant differences in the variables: disorientation; attributions due to uncontrollable causes; lack of perseverance (Table 6).

\subsection{Cluster description}

Table 4 summarises the average scores and the standard deviations of the three groups in the cluster and criterion variables.

Table 4. Results of multivariate post-hoc between cluster 1 and 2: univariate effects

\begin{tabular}{|c|c|c|c|c|c|c|}
\hline Dependent Variable & Type III Sum of Squares & df & Mean Square & $\mathrm{F}$ & Sig. & Partial $\eta^{2}$ \\
\hline Average grades in Math and Italian & 42,100 & 1 & 42,100 & 48,675 &, 000 &, $106^{b}$ \\
\hline Elaboration strategies & 548,429 & 1 & 548,429 & 170,883 &, 000 & ,294 a \\
\hline Self-regulation & 977,004 & 1 & 977,004 & 413,338 & .000 & 502 a \\
\hline Disorientation & 482,408 & 1 & 482,408 & 202,542 &, 000 & ,331 a \\
\hline Collaboration & 22,207 & 1 & 22,207 & 6,132 & 014 & $015^{c}$ \\
\hline Use of semantic-graphic organisers & 153,664 & 1 & 153,664 & 42,055 &, 000 &, 093 b \\
\hline Concentration difficulties & 250,830 & 1 & 250,830 & 74,901 &, 000 & ,154 a \\
\hline Self-interrogation & 222,346 & 1 & 222,346 & 57,001 &, 000 & $122^{\mathrm{b}}$ \\
\hline Anxiety & 39,251 & 1 & 39,251 & 14,449 &, 000 &, $034 \mathrm{c}$ \\
\hline Volition & 1118,762 & 1 & 1118,762 & 491,455 &, 000 &, $545^{\text {a }}$ \\
\hline Attribution to controllable causes & 480,390 & 1 & 480,390 & 176,232 & .000 & 301 a \\
\hline Attribution to incontrollabile causes & 261,623 & 1 & 261,623 & 87,826 &, 000 & 176 a \\
\hline Lack of perseverance & 570,669 & 1 & 570,669 & 236,741 &, 000 & 366 a \\
\hline Self-competence & 244,081 & 1 & 244,081 & 78,598 & .000 & 161 a \\
\hline Emotional interferences & 27,141 & 1 & 27,141 & 9,122 & 003 & $.022^{c}$ \\
\hline
\end{tabular}


Table 5. Results of multivariate post-hoc between cluster 1 and 3: univariate effects

\begin{tabular}{|c|c|c|c|c|c|c|}
\hline Dependent Variable & Type III Sum of Squares & $\mathrm{df}$ & Mean Square & $\mathrm{F}$ & Sig. & Partial $\eta^{2}$ \\
\hline Average grades in Math and Italian & 25,694 & 1 & 25,694 & 28,891 &, 000 &, $060^{b}$ \\
\hline Elaboration strategies & 155,938 & 1 & 155,938 & 49,243 &, 000 &, $098 \mathrm{~b}$ \\
\hline Self-regulation & 218,924 & 1 & 218,924 & 100,769 &, 000 & 182 a \\
\hline Disorientation & 593,031 & 1 & 593,031 & 308,694 &, 000 &, 405 a \\
\hline Collaboration & 3,413 & 1 & 3,413 & 843 &, 359 &, 002 \\
\hline Use of semantic-graphic organisers & 2,808 & 1 & 2,808 & ,717 & 398 & .002 \\
\hline Concentration difficulties & 554,035 & 1 & 554,035 & 183,249 &, 000 & ,288 a \\
\hline Self-interrogation & 2,783 & 1 & 2,783 &, 780 & ,377 & 002 \\
\hline Anxiety & 838,213 & 1 & 838,213 & 323,931 &, 000 & $416^{\text {a }}$ \\
\hline Volition & 239,547 & 1 & 239,547 & 101,728 & .000 & 183 a \\
\hline Attribution to controllable causes &, 086 & 1 & 086 &, 027 & 868 &, 000 \\
\hline Attribution to incontrollabile causes & 374,124 & 1 & 374,124 & 137,576 &, 000 &, 233 a \\
\hline Lack of perseverance & 522,259 & 1 & 522,259 & 248,771 &, 000 &, 354 a \\
\hline Self-competence & 92,584 & 1 & 92,584 & 29,345 &, 000 &, 061 b \\
\hline Emotional interferences & 407,591 & 1 & 407,591 & 150,257 & 000 & 249 a \\
\hline
\end{tabular}

Table 6. Results of multivariate post-hoc between cluster 2 and 3: univariate effects

\begin{tabular}{|c|c|c|c|c|c|c|}
\hline Dependent Variable & Type III Sum of Squares & df & Mean Square & $\mathrm{F}$ & Sig. & Partial $\eta^{2}$ \\
\hline Average grades in Math and Italian & 2,863 & 1 & 2,863 & 3,700 & 055 &, $010^{c}$ \\
\hline Elaboration strategies & 125,762 & 1 & 125,762 & 39,087 & ,000 & , 100 b \\
\hline Self-regulation & 276,005 & 1 & 276,005 & 133,817 &, 000 & $277^{\text {a }}$ \\
\hline Disorientation & ,357 & 1 & ,357 & 119 & ,730 &, 000 \\
\hline Collaboration & 37,096 & 1 & 37,096 & 9,939 & ,002 &, $028^{c}$ \\
\hline Use of semantic-graphic organisers & 174,827 & 1 & 174,827 & 50,527 &, 000 & ,126 b \\
\hline Concentration difficulties & 32,351 & 1 & 32,351 & 9,456 & ,002 &, $026^{\mathrm{c}}$ \\
\hline Self-interrogation & 243,341 & 1 & 243,341 & 78,685 & ,000 & ,184 a \\
\hline Anxiety & 381,072 & 1 & 381,072 & 139,342 & ,000 & ,285 a \\
\hline Volition & 327,274 & 1 & 327,274 & 134,690 & ,000 & ,278 a \\
\hline Attribution to controllable causes & 420,862 & 1 & 420,862 & 145,216 & ,000 & ,293 a \\
\hline Attribution to incontrollabile causes & 2,818 & 1 & 2,818 & ,774 & ,379 & 002 \\
\hline Lack of perseverance & 6,477 & 1 & 6,477 & 2,324 & 128 & ,007 \\
\hline Self-competence & 40,270 & 1 & 40,270 & 12,748 & ,000 &, $035^{c}$ \\
\hline Emotional interferences & 514,865 & 1 & 514,865 & 215,865 & ,000 & ,381 a \\
\hline
\end{tabular}

\subsection{Cluster 1 "Effective students"}

Students of the first cluster show higher academic performances compared to the other two groups. With regard to the cognitive factors of self-regulation in learning, students of cluster 1 demonstrate more differentiated strategies than the other two groups since they obtained higher average scores in strategies of information and self-regulation elaboration. These students resulted less disoriented as well, and with fewer concentration difficulties than the students in the other two groups. Finally, the students in the latter cluster, evidence a better use of semantic organisation factors and selfquestioning, while there is no differentiation between them and cluster 3 . Taking into account the affective dimensions of regulation in learning, their level of volition was higher, their internal locus was greater and they had a better sense of competence compared to the two other groups. It would seem, therefore, that students in cluster 1 had a more stable motivational structure. Regarding to emotional control, the students in this group were less anxious than the other students. 


\subsection{Cluster 2 "Demotivated, disoriented and detached students"}

The students' behaviour in this cluster seems to be the opposite of those in cluster 1. Besides having a lower performance level, they obtained a lower result on the cognitive and motivational scores, and higher scores on the variables relative to the difficulties of emotional management. On the contrary, these students' academic performance, their level of disorientation, their external locus and their perseverance level did not differ from that of the cluster 3 students.

\subsection{Cluster 3 "Anxious students"}

Regarding to the academic performances, students show a lower average than the students in cluster 1 , but they do not differ from those in cluster 2. This group of students can be described starting from the converging points with the other two clusters. With regard to cognitive factors of regulating learning they demonstrated a level of disorientation similar to the students in group 2 and a similar average score to the students in group 1 in factors relative to collaboration, use of semantic organisers and self-monitoring. Regarding affective dimensions, these students obtained a score similar to that of group 1 in factors relative to attribution to controllable causes and in the same way, obtained an average score similar to group 2 in attribution to uncontrollable causes and lack of perseverance. They displayed a higher average score compared to the other two clusters in the competencies regarding difficulties of concentration, anxiety and emotive interference, the latter having effects of extensive dimensions with respect to cluster 2.

Regarding the other variables, these students are located at the intermediate level having a lower score than the cluster 1 students, but superior to those in cluster 2 .

\section{Discussion}

The aims of this research were to highlight the presence of homogenous sub-groups of students on metacognitive, self regulatory and motivational functioning and to analyse the relationship between the use of study strategies and academic performance. The results of the cluster analyses demonstrate that it is possible to identify different typologies of students insofar as the use of strategies is concerned. Through double cross-classification it was possible to establish that the use of three clusters was the most stable solution. The multivariate analyses revealed the different role of the variables considered in the group differentiations.

Academic performance is more than sufficiently positioned in all three of the clusters. The students of cluster 1 , ("effective students"), are characterised by a better performance and a better strategic and emotive-motivational profile than the other two clusters. It is possible to trace the typical characteristics of those students in the literature described as the good strategy users (Borkowski, 1988); efficacious students who, besides using good study strategies, show an adequate motivational and emotive style towards study. Cluster 1 students employ self-regulation strategies; they consider themselves involved in academic tasks out of interest and personal satisfaction; furthermore, they actively promote their own learning (De Stasio and Di Chiacchio,2008; Moliterni et al.2011; Zimmerman, 1999). A number of studies so far carried out have emphasised how active involvement in learning influences the level of academic performance (Ablard, 1998; Benevene, Cortini, Di Lemma, 2015; Clearly and Chen 2009). In line with what has been outlined by several studies (Garcia and Pintrich, 1996; Pintrich and De Groot, 1990, Pintrich and Schrauben, 1992; Pintrich and Zusho 2002), cluster 1 students, ("effective students"), demonstrate alongside self-regulation, a good sense of self-efficacy.

Cluster 2 students "demotivated, disoriented and detached students" demonstrate an opposite profile to those in cluster 1. They display a lower academic performance compared to the efficient students of cluster 1 , showing a scarce utilisation of study strategies, demonstrating difficulty in maintaining a stability in the academic commitment taken and in the end, seem little motivated to study with efficacy.

It is pointed out that there is a lack of study organisation among these students; a tendency to approach learning tasks somewhat passively, out of habit with a low level of reflection and planning (Moè, Cornoldi, De Beni, 1998; Proctor et al.2006). Demotivation and the failure to vary the commitment to other disciplines can be translated into feelings of insecurity, which in turn may be caused by lack of commitment (Busato et al. 2000; De Stasio and Di Chiacchio 2008, Lorusso, 1991).

Students in cluster 3 ("anxious students") showed lower academic performances compared to those students in cluster 1, but they were no different from the students of cluster 2. They demonstrated a discrete motivational and strategic capacity, which placed them at an intermediate level in comparison with the other groups. Affective regulation 
connected to their study activity showed a relative complexity. They were more anxious with major concentration difficulties and susceptible to emotive interference to a greater degree than cluster 2 students.

The literature relates how the presence of anxiety and the lack of concentration in students with an adequate cognitive capacity can interfere on the positive outcome of academic performance (Pintrich and De Groot, 1990; Benjamin, McKenzie and Lin, 1987; Tobias, 1985).

In sum, the results have highlighted the profile of student efficacy on the one hand, with a efficacious strategic and motivational aspects related to study. On the other hand, there are two profiles of weaker students: first type shows an insufficiency in both cognitive and affective-motivational aspects, the second one evidences an inadequacy of emotion regulation compensated for by sufficient cognitive strategies.

One interesting fact to note it is that the effect of marks: academic performance explained only $8.7 \%$ of the variables recorded among the groups of the students involved in the survey, playing, therefore, a role of average importance. The difference between cluster 2 and 3, as previously described, was not significant. In our opinion, this fact could have important implications: if we limit ourselves to the marks, then we will be misled by the fact that the students in clusters 2 and 3 had fairly similar performance results. In keeping with previous research, it is interesting to emphasise that although academic success is linked with self-regulation strategies, there are significant differences among students with a good performance rate. The different use of metacognitive and self regulated learning strategies can generate different performance profiles in the long term, which would suggest that some students might continue to excel, while others might risk being underachievers (Reis, 2000; Risenberg and Zimmerman, 1992; Schwinger and StiensmeierPelster 2012; Siegler 1988, Şimşek and Balaban 2010).

The cluster analysis results and in particular the Manova outcomes, have highlighted the fact that these two groups of students (group 2 and 3), differ in the cognitive and affective-motivational aspects of learning regulation; a more in depth examination of their profiles could provide a notable contribution to the planning of interventions aimed at improving students' academic performance.

There are, however, several limitations to the results of this study. Above all, as in other research, the instrument of self-reporting was used to evaluate the motivational and cognitive components; information gathered in this way should be integrated with other data derived from elicited stimuli and spontaneous summaries concerning study habits. A second limitation to the generalisation of the results is due to the fact that the student sample was taken from Year 4 and 5 secondary institutions. It would be interesting to study the metacognitive and motivational characteristics in depth over a longer period of school attendance in the future.

\section{References}

Ablard, K.E., \& Lipschuitz, R.E. (1998). Self-regulated learning high-achieving students: Relations to advanced reasoning, achievement goals, and gender. Journal of Educational Psychology, 90, 94-101.

Anderson, J.R. (1983). The architecture of cognition. Cambridge: Harvard University Press.

Anderson, J.R. (1990). Cognitive psychology and its implications. (3rd ed.). New York: Freeman.

Artino, A. (2009). Think, feel, act: Motivational and emotional influences on military students' online academic success. Journal of Computing in Higher Education, 21, 146-166.

Barbaranelli, C. (2006). Analisi dei dati con SPSS II. Analisi multivariate. Milano: LED.

Benevene, P., Cortini, M., \& Di Lemma, L. (2015). Child Labor and Adolescent Labor: May They Become a Learning Opportunity? The International Journal of Pedagogy and Curriculum, 22, 15-24.

Benjamin, M., McKeachie, W.J., \& Lin Y.G. (1987). Two types of test-anxious students: Support of an information processing model. Journal of Educational Psychology,79,131-136.

Bol, L., \& Garner, J. K (2011). Challenges in supporting self-regulation in distance education environments. Computer in Higher Education, 23, 104-123.

Bransford, J. D., Brown, A. L., \& Cocking, R. R. (1999). How people learn: Brain, mind, experience, and school. National Academy Press.

Borkowski, J.G. (1988). Metacognizione e acquisizione di forza (empowerment) : Implicazioni per l'educazione di alunni con handicap e difficoltà di apprendimento. In C. Cornoldi, R.Vianello (Eds), Handicap comunicazione e linguaggio,(pp.36-38), Bergamo: Juvenilia.

Borkowski, J.G , Johnston M.B., \& Reid, M.K.(1987). Metacognition, motivation and controlled performance. In S.J. Ceci (Eds), Handbook of cognitive, social and neuropsychological aspects of learning disabilities (pp.147-174). Hillsdale ,NJ: Lawrence Erlbaum.

Borkowsky J.G., \& Muthukrishna, N. (1994). Lo sviluppo della metacognizione nel bambino: un modello utile per introdurre l'insegnamento metacognitivo in classe. Insegnare all'handicappato,8, 229-251.

Brown, A.(1980). Metacognitive development and reading. In R.J.Spiro, B.Bruce \& W.Brewer (Eds)Theoretical issues in reading comprehension (pp.453-481). Hillsdale, NJ: Erlbaum. 
Busato, V.V., Prins, F.J., Elshout J.J., \& Hamaker, C. (2000). Intellectual ability, learning style, personality, achievement motivation and academic success of psychology students in higher education. Personality and Individual Differences, 29,1057-1068.

Cleary, T., \& Chen, P, P. (2009). Self-regulation, motivation, and math achievement in middle school: Variations across grade level and math context. Journal of School Psychology, 47, 291-314.

Cleary, T. J., \& Zimmerman, B. J. (2012). A cyclical self-regulatory account of student engagement: Theoretical foundations and applications. In Handbook of research on student engagement (pp. 237-257). Springer US.

Credé, M., \& Phillips, A. L. (2012). A meta-analytic review of the Motivated Strategies for Learning Questionnaire. Learning and Individual Differences, 21, 337-346.

De Beni, R., \& Pazzaglia, F. (2003). La teoria metacognitiva applicata alla comprensione della lettura: dalla riflessione sulle conoscenze all'introduzione di variabili emotivo-motivazionali. In O. Albanese, P.A. Doudin, D. Martin (Eds) Metacognizione ed educazione (pp.137-146). Processi, apprendimenti, strumenti. Milano: Franco Angeli.

De Stasio, S., \& Di Chiacchio, C. (2008).Profili di rendimento scolastico e di utilizzo di strategie di apprendimento: una valutazione multidimensionale in studenti di scuola superiore. Orientamenti pedagogici,55, 493-505.

Di Chiacchio, C., \& De Stasio, S.(2011) Stili metacognitivi e successo scolastico. .Quali implicazioni nella pratica orientativa? In Petruccelli, F., D'Amario B., Giordano V. (Eds) (pp.176-185), La scelta formativa: attitudini, competenze e motivazioni, Milano: Franco Angeli.

Entwistle N.J. , \& Brennan, T.(1971). The academic performance of students: two types of successful students. British journal of educational psychology, 41, 268-276.

Flavell, J.H. (1979). Metacognition and cognitive monitoring. American Psychologist, 34,906-911.

Garcia, T., \& Pintrich, P. R. (1996). Assessing students' motivation and learning strategies in the classroom context: The motivated strategies for learning questionnaire. In Alternatives in assessment of achievements, learning processes and prior knowledge (pp. 319-339). Springer Netherlands.

Johnston W.A., \& Dark W.J. (1986). Selective attention. Annual of Review of Psychology, 37,43-75.

Lorusso M.L.(1991),Gli aspetti emotivo-motivazionali dei disturbi dell'apprendimento. In C. Cornoldi(Eds ), I disturbi dell'apprendimento: Bologna,ll Mulino.

Moliterni, P., De Stasio, S., Carboni, M.,\& Di Chiacchio, C.(2011).Il Learning and Study Strategies Inventory (LASSI): un'applicazione su un campione di studenti universitari italiani.Orientamenti pedagogici,58, 387-399.

Moliterni,P., De Stasio, S., \& Carboni,M.(2011). Studiare all'università. Milano: Ed.Franco Angeli

Moè A., Cornoldi C., \& De Beni R. (1998). Incoerenza strategica, metodo di studio e insuccesso scolastico. Archivio di Psicologia, Neurologia e Psichiatria, 1, 567-576.

Moè A., \& De Beni R. (2003). Strategie e metodi di studio: aspetti strategici, metacognitivi e motivazionali. In O. Albanese, P.A. Doudin, D. Martin (Eds) Metacognizione ed educazione. Processi, apprendimenti, strumenti. Milano: Franco Angeli.

Montalvo, F. T., \& Torres, M. C. (2004). Self regulated learning: current and future direction. Electronic journal of Research in Educational Psychology, 2, 1-34.

Pellerey, M. (1996). Questionario sulle Strategie di Apprendimento (QSA), Roma, LAS.

Pintrich, P.R., \& De Groot, E.V. (1990) Motivational and Self-regulated learning components of classroom academic performance. Journal of Educational Psychology,82,33-40.

Pintrich P.R., \& Schrauben B. (1992), Students motivational beliefs and their cognitive engagement in classroom academic tasks. In D.H. Schunk, J.L. Meece (Eds.), Student perception in classroom (pp. 149-183), Hillsdale: Erlbaum.

Pintrich, P. R. (2000). Multiple goals, multiple pathways: the role of goal orientation in learning and achievement.Journal of educational psychology, 92, 544-555.

Pintrich P.R., Zusho A. (2002), The development of academic self regulation: the role of cognitive and motivational factors. In A. Wigfield, J.S. Eccles (Eds.), Development of achievement motivation. A volume in the educational psychology series. (pp. 249284) San Diego, CA, US, Academic Press.

Proctor, B.E., Prevatt, F., Adams, K., Hurst, A., \& Petscher Y. (2006). Study skills profiles of normal-achieving and academicallystruggling college students. Journal of College Student Development, 47, 37-51.

Reis, S.M. (2000). Underachievement of Gifted Student: Many Frustrations and Few Solutions. New Jersey Association for Gifted Children. 8, 4-16.

Schwinger, M., \& Stiensmeier-Pelster, J. (2012). Effects of motivational regulation on effort and achievement: A mediation model. International Journal of Educational Research, 56, 35-47.

Siegler, R.S. (1988), Individual differences in strategy choice: good students, not so good students, and perfectionists. Child Development,59, 129-143.

Şimşek, A., \& Balaban, J. (2010). Learning strategies of successful and unsuccessful university students. Contemporary Educational Technology, 1, 36-45.

Schunk D., \& Zimmerman, B.J. (1994). Self-regulation of learning and performance: Issues and educational applications, Hillsdale: Erlbaum.

Tobias, S. (1985). Test anxiety: Interference, defective skills, and cognitive capacity. Educational Psychologist, 20, 135-142.

Winne, P. (1996). A metacognitive view of individual differences in self-regulated learning. Learning and individual differences,8, 327-353.

Zimmerman, B.J. (1989). A social cognitive view of self- regulated academic learning. Journal of Educational Psychology, 81, $329-339$.

Zimmerman, B.J. (1999). Le abilità di studio e le strategie di auto-regolazione dell'apprendimento. Psicologia dell'Educazione e della Formazione, 1, 25-49. 